\title{
LA INTERNACIONALIZACIÓN DEL MAGISTERIO AMERICANO: PROPUESTAS EDUCATIVAS Y TENSIONES POLÍTICAS
}

\author{
Alexandra Pita González ${ }^{1}$ \\ Universidad de Colima - México \\ apita@ucol.mx
}

Recepción: 13/09/2010

Evaluación: 09/03/2011

Aceptación: 22/06/2011

Artículo de Reflexión

\section{RESUMEN}

Durante la década de 1920 se suscitaron numerosas propuestas educativas que buscaban modificar radicalmente la enseñanza tradicional. Entre ellas esta aquellas que recibieron el impacto de la revolución rusa, ya sea para seguir el camino trazado por una nueva pedagogía proletaria o para cuestionarse la necesidad de una educación que tuviera como objetivo el cambio social. Para llevar a cabo el cambio anhelado era necesario crear organizaciones de maestros regionales e internacionales, que en diversos congresos presentaron sus propuestas educativas y enfrentaron una serie de batallas políticas que dejan traslucir las fuertes tensiones del campo educativo e intelectual. En América Latina, un espacio privilegiado para observar este debate fue la Internacional del Magisterio Americano, organización que tuvo visibilidad inicialmente a través de dos convenciones realizadas a fines de la década de 1920, donde se reunieron un número importante de maestros para debatir la situación de la educación pública en estos países.

Palabras clave: Revista Historia de la Educación Latinoamericana, conferencias políticas y de educación, organizaciones de maestros, sindicalismo, educación social y educación proletaria.

1 Doctora en Historia por El Colegio de México, profesora-investigadora titular de tiempo completo de la Universidad de Colima, miembro del Sistema Nacional de Investigadores nivel 1. Línea de investigación: historia intelectual de América Latina. 


\title{
THE AMERICAN INTERNATIONAL TEACHING: EDUCATIONAL PROPOSALS AND POLITICAL TENSIONS
}

\author{
Alexandra Pita González \\ Universidad de Colima-México \\ apita@ucol.mx
}

\begin{abstract}
During the 1920s, raised numerous educational proposals that sought to radically change the traditional teaching. Between them these those receiving the impact of the Russian revolution, either to follow the path set by a new proletarian education or to question the need for an education that would seek social change. To carry out the desired change was necessary to create regional organizations and international teachers, who at various educational conferences and presented their proposals faced a series of political battles that belie the tensions of the educational field.
\end{abstract}

Key words: Journal of Latin American Education History political and educational conferences, teacher organizations, syndicalisms, social education, education proletarian

\section{A INTERNACIONALIZAÇÃO DO MAGISTÉRIO AMERICANO: PROPOSTAS EDUCATIVAS E TENSÕES POLÍTICAS}

\author{
Alexandra Pita González \\ Universidade de Colima - México \\ apita@ucol.mx \\ RESUMO
}

Durante a década de 1920 foram suscitadas numerosas propostas educativas que buscavam modificar radicalmente o ensino tradicional. Entre elas estão aquelas que receberam o impacto da revolução russa, seja para seguir o caminho traçado por uma nova pedagogia proletária, seja para questionar a necessidade de uma educação que teve como objetivo a transformação social. Para possibilitar a mudança desejada era necessário criar organizações de professores regionais e internacionais, que em diversos congressos apresentaram suas propostas educativas e enfrentaram uma série de batalhas 
políticas que deixam transluzir as fortes tensões do campo educativo e intelectual. Na América Latina, um espaço privilegiado para observar este debate foi a Internacional do Magistério Americano, organização que teve visibilidade inicialmente através de duas convenções realizadas no fim da década de 1920, aonde se reuniram um número importante de professores para debater a situação da educação pública nestes países.

Palavras-chave: Revista História da Educação Latino-americana, conferências políticas e de educação, organizaçôes de professores, sindicalismo, educação social e educação proletária.

\section{INTRODUCCIÓN}

Tras el fin de la Primera Guerra Mundial y el estallido de la Revolución Rusa, el mundo occidental estaba convulsionado y buscaba desesperadamente un cambio que marcara el inicio de una nueva época. Muchos creyeron que para que este cambio se efectivizara era indispensable transformar la educación. En América Latina, el panorama no era menos complejo, al sumar estas experiencias otras propias, que daban muestras del aún en proceso estado de construcción nacional y del enfrentamiento de distintos grupos ideológicos. Los maestros no fueron ajenos al cuestionamiento del viejo orden y el intento de fundar uno nuevo, conformando organizaciones en las cuales se presentaron propuestas educativas que no exentas de una determinada posición ideológica implicaron una serie de enfrentamientos y tensiones políticas.

Por ello el objeto de este trabajo es analizar la Internacional del Magisterio Americano (IMA) a través de sus dos convenciones, la de Buenos Aires (1928) y la de Montevideo (1930), los cuales servirán de ejes cronológicos y temáticos para organizar el desarrollo del trabajo en dos apartados. A este análisis sumamos la referencia a otros Congresos, realizados por organizaciones con las cuales existió una fuerte tensión como es el caso de la Internacional de los Trabajadores de la Enseñanza (ITE) y la Confederación Sindical Latino Americana (CSLA).

Así, tomando las observaciones de la nueva historia política de la educación ${ }^{2}$, pretendemos aportar un aspecto poco explorado tanto por la falta de conocimiento sobre la labor desarrollada por la IMA, como por la ausencia de estudios sobre las publicaciones periódicas donde se

2 Para ver un planteamiento claro sobre la nueva historia política de la educación remitimos a FERNÁNDEZ SORIA, J. M. (2006): "La nueva historia política de la educación", en: Historia de la educación: revista interuniversitaria. No. 25. Universidad de Salamanca, pp. 71-103. 
difundieron o cuestionaron estas ideas educativas Liberación. Órgano de la IMA, el Boletín de los Trabajadores de la Enseñanza y El Trabajador Latinoamericano, órgano de la CSLA.

Como unidad de análisis el Congreso Científico permite entender la asociación de sujetos que en nombre propio o en representación de un colectivo (instituciones, organizaciones, gremios, secciones, etc.,) se reúnen periódicamente para debatir un temario previamente acordado y conformar un consenso que permita producir ciertas recomendaciones científicas. Dada esta singularidad es necesario cuestionarse quiénes son los participantes y cómo interactúan: en nombre de quién asisten, si fueron invitados expresamente, si son adherentes, si presentan comunicaciones científicas y proponen resoluciones, si son nombrados para ocupar algún cargo dentro del evento. Asimismo, para entender la puesta en escena es preciso conocer las características que rigen dichos eventos, esto implica preguntarse por las reglas implícitas que se siguen para pautar el comportamiento de los participantes, el principio de autoridad y el tipo de valor que predomina: la civilización y urbanidad, la unidad política, la actividad desinteresada o la solidaridad humana, entre otros ${ }^{3}$.

Consideramos que al recuperar estos espacios públicos como escenarios donde circularon personajes e ideas pedagógicas, se dirimieron posturas ideológicas y diferencias políticas, podemos prestar atención a aquellos rasgos y referentes que permiten delimitar los temas de interés y las tendencias. Con ello no pretendemos agotar las múltiples posibilidades que existe al explorar los Congresos Educativos sino tan sólo señalar su potencialidad ${ }^{4}$.

\section{Maestros y pedagogía social}

Del 8 al 19 de enero de 1928 se reúnen en Buenos Aires delegaciones nacionales e internacionales para inaugurar el Primer Congreso de Maestros de América, evento en el cual tras una serie de debates políticos y propuestas educativas se fundaría la Internacional del Magisterio Americano (IMA).

Como puede observarse en el temario del evento, sus participantes pretendían discutir una amplia gama de aspectos relacionados con la

3 CALVO ISAZA, Óscar Iván. (2005): Conocimiento desinteresado y ciencia americana. El congreso Científico (1898-1916) presentado en el seminario de historia intelectual de El Colegio de México, pp. 3-4. Consultado en http:// shial.colmex.mx/textos/OscarCalvo2005.pdf

4 Un ejemplo de las ricas y variadas posibilidades que tiene el analizar las Conferencias Educativas, así como de las precauciones utilizadas para su estudio, lo encontramos en el trabajo sobre las Conferencias de Educación de la OIE en décadas recientes. Ver, BELLO, María Eugenia. (2003): Educación y globalización. Los discursos educativos en Iberoamérica. Madrid, Anthropos Editorial. 
actividad docente no sólo desde una perspectiva educativa sino también política: finalidades de la nueva educación y los derechos del niño; unidad en el proceso educativo; relaciones con la escuela y el Estado y régimen de gobierno; unidad en el proceso educativo; actitud del maestro frente al imperialismo y las dictaduras; contribución del maestro al establecimiento de la paz y la justicia social; unión de los trabajadores intelectuales y manuales; medios de combatir el analfabetismo en nuestro país y situación de los indígenas; organización nacional e internacional del magisterio y a modo de cierre, modos de poner en práctica lo establecido por la Convención ${ }^{5}$.

\section{El cruce discursivo entre educación y política será como veremos} una constante en el desarrollo del evento. Posiblemente este hecho este relacionado a que en su organización tuvo una activa participación Julio R. Barcos, intelectual y pedagogo anarquista, quien una vez terminado el acto fue elegido como miembro del Consejo Directivo de la $\mathrm{IMA}^{6}$.

Asistieron las delegaciones de México, Panamá, Guatemala, Perú, Bolivia, Chile, Argentina, Uruguay y Paraguay, así como un delegado representando a la Internacional de Trabajadores de la Enseñanza de París. Además, enviaron delegados los gremios de profesores de varias provincias argentinas y de la capital federal. MARTÍNEZ TRUCCO, Amelia. (2004): Acción Gremial del Magisterio de Santa Fe. Su trayectoria y aporte en la construcción del sistema educativo. Santa Fé: Universidad Nacional del Litoral, p. 58.

6 Julio Barcos (Coronda, Santa Fe, 1883- Buenos Aires, 1960) desde joven se inició en el anarquismo colaborando en la primera década del siglo en diversas publicaciones libertarias (La Protesta, el diario de Buenos Aires, la revista Ideas y Figuras, Letras. Asumió el cargo de Director de la Escuela Laica de Lanús y luego orientó el proyecto de la Escuela Moderna de Buenos Aires (19081909), participando activamente en la Liga de Educación Racionalista. Desde sus publicaciones difundió sus ideas pedagógicas recibiendo por ello críticas de los defensores de la enseñanza estatal y religiosa. Fomentó la agremiación de los maestros a través de la Liga Nacional de Maestros (1910) que al año siguiente dio origen a la Federación Nacional del Magisterio de la República Argentina. Editó la revista Renovación (1914) y dirigió la Escuela Popular (1912-1914). Fue uno de los pocos anarquistas que defendió la causa aliada durante la Primera Guerra Mundial y en 1917 la revolución rusa. En 1918, Barcos inicio un viaje por América Latina llegando primero a Caracas donde tras su expulsión fue a Centroamérica con el puertorriqueño Nemesio Canales para difundir un plan "Bolivariano y L Grupo de investigación HISULA eniniano". De regreso en Buenos Aires, Barcos continuó con la publicación Cuasimodo iniciada en Panamá junto a Canales y entre 1922 y 1924, editó Las Grandes Obras (folletos anarquistas a bajo costo), formando además parte de la Internacional del Magisterio Americano. A fines de la década adhirió al radicalismo de filiación yrigoyenista, accediendo al Consejo Nacional de Educación. Tras el golpe militar de 1930 conspiró junto a militares rebeldes para derrocar al Gral Uriburu y el gobierno de Agustín P. Justo. En la década siguiente fundó la empresa editorial La Luz del Día, la cual edito varias obras. Además de su activa participación en publicaciones periódicas, Barcos publicó numerosos libros entre los cuales los más significativos para su batalla educativa fueron: La escuela moderna s/f (1914), proyecto de ley orgánica para la instrucción pública, BA 1920; Cómo educa el Estado a tu bijo BA, 1927; Régimen federal de la enseñanza, BA, 1940. TARCUS, Horacio. (2007): Diccionario biográfico de la izquierda argentina: de los anarquistas a la "nueva izquierda" 1870-1976. Buenos Aires, Emecé. 
Ambas participaciones daban a la reunión un carácter antiimperialista, el cual no era extraño en cuanto existía tanto en el ambiente nacional como en el regional, serios cuestionamientos en torno al intervencionismo norteamericano en América Latina y como contraparte, una defensa a la integración latinoamericana como medida defensiva regional que permitiera mantener a salvo a la autonomía política y económica ${ }^{7}$. A nivel nacional, tras el asenso del radicalismo a la presidencia en 1916 el panorama político, social y económico era complejo ante la aparición de movimientos violentos de protesta que involucraba a distintos grupos sociales. Uno de ellos, el de reforma universitaria conmocionó a una clase media en ascenso que buscaba revertir el orden tradicional oligárquico, y se convirtió en una escuela ideológica para los sectores avanzados de la pequeña burguesía ${ }^{8}$. Buenos Aires era entonces un ambiente perfecto para un encuentro de esta naturaleza en cuanto, amén de su reconocida y heterogénea tradición política de izquierda (donde convivían desde anarquistas, socialistas y comunistas hasta estudiantes del movimiento reformista), se iniciaba la segunda presidencia de Hipólito Yrigoyen y con ello un fuerte debate sobre la nacionalización del petróleo?

No es extraño entonces que para iniciar la Convención se realizara un acto de homenaje a dos educadores europeos (Ellen Key y Pestalozzi) y una declaración de solidaridad con el pueblo de Nicaragua ante la invasión de los EUA. Como tampoco lo es el que los congregados partieran el debate con el principio de que la educación debía ser pública pero autónoma esto es, apoyada por el gobierno pero dirigida por un consejo nacional de educadores, que rigiesen según las normas y leyes propias del magisterio e integral, lo que significaba que la educación pública debía velar no sólo por el nivel básico sino que debía pensarse como una formación continua desde la infancia hasta la juventud (incluyendo desde la primaria hasta la universidad). Para ello se tomó como ejemplos la "acción innovadora" del México revolucionario, el código educativo de Costa Rica y el plan de reconstrucción nacional elaborado por los profesores de Chile.

Estos principios ponían de manifiesto el interés por adquirir un espacio mayor de decisión en los sistemas de educación, los cuales por distintas

La década de 1920 exhibe una enorme riqueza en cuanto al pensamiento latinoamericanista que reivindicando el ideal bolivariano planteaba la urgente necesidad de integrar estas nacionales ante el temor de ser convertidas nuevamente en colonias por el imperialismo norteamericano. PITA GONZÁLEZ, Alexandra. (2009): La Unión Latino Americana y el Boletín Renovación. redes intelectuales y revistas culturales en la década de 1920. México, El Colegio de México, La Universidad de Colima.

8 PORTANTIERO, Juan Carlos. (1978): Estudiantes y política en América Latina. El proceso de la reforma universitaria 1918-1938. México, Siglo XXI Editores, p. 14.

9 Ver, ROCK, David. (1996): El radicalismo argentino. Buenos Aires, Amorrortu Editores. 
vías y momentos habían tendido en Latinoamérica a un modelo estatizado y centralista ${ }^{10}$. Es evidente que las ideas y experiencias del ideario libertario de Julio Barcos jugaron un papel importante en estas expresiones, en especial aquellas que hacían a la defensa del cogobierno y de la autonomía que habían sido concentradas y publicadas recientemente en su libro Cómo educa el Estado a tu bijo ${ }^{11}$.

Así, los congregados cuestionaban tanto la educación impartida por la Iglesia y el Estado, en cuanto ambas inducen a relaciones de dominación clasista que lleva a la miseria de la humanidad favoreciendo las guerras y otras formas de búsquedas del poder. Declaran que la finalidad de la nueva educación debe favorecer el desarrollo del individuo, mediante la enseñanza anti dogmática y científica, co educativa (incluyendo a los padres y al resto de la comunidad) que favorezca la solidaridad y la libertad. Para ello es indispensable concretar los derechos del niño en un código que

${ }^{10}$ Para el caso argentino, Juan Carlos Tedesco asume que este proceso se da claramente a fines del siglo XIX cuando tras la aprobación de la ley 1420 (educación básica) y la ley Avellaneda (educación universitaria), el Estado pasó a ejercer un control tanto de la educación impartida en establecimientos públicos como privados mediante una serie de elementos entre los que se destacan el nombramiento de un Consejo Nacional de Educación, encargado a su vez de nombrar a los demás cargos magisteriales. TEDEESCO, Juan Carlos. (1982): Educación y sociedad en la Argentina (1880-1900). Buenos Aires, Centro Editor de América Latina, pp. 94-104.

11 En él, Barcos reafirma el ideario libertario que basado en la idea de que la humanidad se encuentra en un progreso infinito y que para solucionar las desigualdades e injusticias debe transformarse la esencia humana, desde la infancia a través de la educación influenciada por la filosofía positiva (la verdad demostrada y aceptada) fuera de todo dogma religiosos y siguiendo como modelo la pedagogía moderna. Pese a estar integrado en el sistema educativo al momento de su publicación ocupando un cargo de inspector, mantiene su vieja desconfianza en el Estado, acusándolo de pretender monopolizar la enseñanza para mantener una dominación de clase que mantenga al pueblo como un menor indefinidamente. Asimismo, desconfía de los maestros de escuelas oficiales que se encuentran "castrados" por el sistema, convirtiéndose en "maestros-burócratas" que buscan perpetuar el sistema de dominación. Propone como remedio de la educación el que gobierno, los padres de familia y los maestros reformen sustancialmente el contenido pedagógico de la escuela pública, dándole un sentido social y autónomo. Esto implica modificar el interior de la vieja escuela para convertirla en una entidad autónoma (en lo administrativo y económico) dirigida por técnicos- en el sentido de un funcionario especializado- y no por políticos, que incluyera necesariamente la colaboración del pueblo. Así, Barcos rescata del anarquismo su concepto de gobierno en tanto plantea que este sería completamente autónomo a partir de su autogestión y representativo de la comunidad educativa. El nuevo modelo emergente estaba compuesto por dos consejos (de enseñanza primaria y secundaria), siguiendo el modelo de órganos que impuso el movimiento reformista universitario para el gobierno de las universidades e inspirándose en el Código de Instrucción Pública de Costa Rica de 1920 en el cual Barcos había colaborado durante su estancia en aquel país. BARCOS, Julio. (1927): Cómo educa el estado a tu bijo. Buenos Aires, Editorial acción. 
defienda su posibilidad a recibir educación en la medida de sus capacidades, independientemente de sus posibilidades económicas o sociales ${ }^{12}$.

Para garantizar estos derechos era necesario implementar la gradualidad en la enseñanza, lo cual implicaba organizar la enseñanza desde la educación preescolar hasta la universidad, como un sistema unificado subdividido en: jardín de niños y casas para niños abandonados, primaria 6 años donde se implementen todos los avances pedagógicos (Montesorri, Delacroy, etc.,) secundaria de la cual tiene un primer ciclo cultural, mientras el segundo ciclo se bifurcará (según la elección del alumno) en cursos de especialización para estudios universitarios o los de carácter técnico enfocados a la producción. La universidad a su vez, siguiendo las ideas del intelectual argentino José Ingenieros se asume "como el motor de la elevación intelectual y técnica del pueblo". En los últimos tres ciclos se deberían agregar espacios "circunescolares" como bibliotecas, cocinas escolares, asociaciones cooperativas, y todo lo que pueda beneficiar a la comunidad en general ${ }^{13}$.

La reacción de la prensa nacional no se hizo esperar publicando artículos hostiles al evento. El conocido diario La Prensa, cuestionó desde su inicio las expresiones y conceptos de los oradores tanto como el ambiente general de incertidumbre sobre "los móviles y propósitos" de la Convención, descubriendo la existencia de una "falsa posición" del orden en que han sido colocados los temas del debate con el fin de provocar "baratas simpatías a favor de un credo libertario y anárquico que no se aviene con la realidad profesional del magisterio y los fundamentos de cualquier sistema racional de educación”. Específicamente se quejan de la protesta por la invasión de los EUA en Nicaragua, así como de la petición que hacían al gobierno argentino de que se perdonara la deuda del Paraguay, adquirida tras la derrota de la Guerra de la triple alianza. Igual de inadecuada les parecía la resolución sobre la "justicia social" en la cual sostenían que era

12 Sintetizando, el código afirma que todo niño tiene derecho a: 1 . ser niño respetando sus intereses y necesidades personales. 2. A una nueva educación apoyada por la ciencia (la sociología, la psicología y la biología). 3. siendo un organismo activo la escuela debe permitirle experimentar "saber hacer". 4. Al trabajo escolar colectivo en grupos pequeños. 5. A trabajar al aire libre y practicar juegos y ejercicios naturales (marchar, nadar, trepar, etc.,).6. A conocer la "cuestión sexual" de manera progresiva "sin misterio ni vergüenza" 7. A ser miembro de una comunidad escolar en la que tenga derechos y obligaciones. 8. A contar con maestros elegidos, ilustrados y bien retribuidos "que crean en los ideales más difíciles de alcanzar". 9. A locales escolares sencillos, alegres e higiénicos. 10. A que cooperen en su educación maestros y padres, "a que colaboren juntos el pueblo y la escuela”. Resolución de la Primera Convención Internacional de Maestros" en Revista de Ciencias Económicas, publicación de la facultad de ciencias económicas, año XVI, No. 78, pp. 1805-1806.

${ }^{13}$ Renovación, año 6, núm. 61, enero 1928, pp. 4 y 5. 
función de los maestros la enseñanza de la moral cívica que fomentara el sentimiento de solidaridad ante la injusticia, la explotación y el atropello a las libertades cívicas y políticas, ni que hablar de la protesta contra las dictaduras en América Latina ${ }^{14}$.

Otro crítica rotunda publica el diario El Orden, al declarar que al agitar al gremio "contra las órdenes sociales de los Estados", los maestros de la Convención carecen de razón perdiendo su visión magisterial "cuando extraviados, pretenden infundir un sistema sectario de cualquier índole en las nuevas tareas docentes". Por este motivo les parece sensato que tras los agitados debates se retiren los educadores argentinos Pablo Pizzurno y la Dra. Rawson de Dellepiane, tras solicitar que la Convención recortara su programa acomodándolo a las circunstancias. Por motivos similares, la publicación aplaudió el retiro de los delegados argentinos de Santa Fe, cuestionando a la Srita. Julia García, única representante santafesina que se quedó hasta el final de la Convención por defender en un artículo la misión pedagógica del Congreso, afirmando que la reacción hostil de la prensa fue tendenciosa al publicar información falsa. La idea de autonomía escolar que defendió la Convención, afirmó la maestra, no es de sectas políticas sino una idea compartida por casi todos los maestros. Para contestar a dicha afirmación, el diario decide hacerle un reportaje interrogándola sobre lo acontecido con la intención de demostrar el fracaso del evento. La maestra santafesina aclaró detalladamente que la confusión fue un caso temporal explotado por la "gran prensa" para provocar el rechazo entre la opinión pública. No contento, el periódico publicó también una entrevista con los dos delegados santafesino que se habían retirado de la Convención, en la cual expresaron su malestar por rechazar a Sanz, representante de la Liga Nacional del Magisterio por ser un conocido anti gremialista y ante el convencimiento del utópico proyecto de Julio Barcos de crear una escuela sobre la base de la "contribución material del Estado, moral de los padres y técnica de los maestros", por ser esta una idea sin ninguna posibilidad de hacerse efectiva de manera inmediata ${ }^{15}$.

Como se observa hasta aquí y pese a las críticas de la prensa oficial argentina, aunque las propuestas de la Convención hagan mención al valor social de la educación y al rechazo de una escuela clasista, hay una marcada ausencia de referencias puntuales al modelo de educación que se estaba llevando a cabo en la URSS. Se evita discutir públicamente sus avances pedagógicos, tanto como definir cuál era la relación con otras instancias

${ }^{14}$ La Prensa, 9, 10, 15, 17 y 18 de enero de 1928. Citado en: MARTínEZ TRUCCO. (2004): Óp., cit, pp. 58-60.

${ }^{15}$ El Orden, 12, 17, 19, 20, 21, 22, 28 y 30 de enero de 1928. Citado en: MARTÍNEZ TRUCCO. (2004): pp. 60- 63. 
internacionales que pretendían agrupar al gremio de la educación como la Internacional de Trabajadores de la Enseñanza $(\mathrm{ITE})^{16}$.

Creada en 1920 durante el Congreso de Burdeos por un grupo de maestros que haciéndose eco del mensaje de Anatole France creían en el papel regenerador que debían de jugar los maestros "con conciencia de clase" para formar en el niño una orientación ideológica que impidiera hacer de él un instrumento de la clase dominante ${ }^{17}$. En su fundación se respetó el que cada sección que se incorporase decidiera mantener su adhesión a la Federación Sindical Internacional (FSI) y la Internacional Sindical Roja (ISR), las cuales respondían a la órbita de la Internacional de Amsterdam (conocida como la nueva o reconstruida II Internacional) y la III Internacional Comunista (Moscú) ${ }^{18}$. Así, en aras de sumar filas la ITE se conformó por aquellos que aceptaran el principio de lucha de clases sin distinción entre la interpretación socialista o comunista. Este intento de autonomía falló al tiempo que los planteamientos fueron inclinándose hacia las directrices de la Internacional Comunista. Este viraje fue visible desde el Congreso de Bruselas (1924) cuando se incorporó la Federación de Maestros de la Unión Soviética, quedando los reformistas o moderados

16 Inicialmente la organización se denominó Internacional de la Enseñanza y desde 1924 pasó a llamarse Internacional de los Trabajadores de la Enseñanza, a propuesta de los delegados rusos recientemente incorporados. DE LUIS MARTÍN, Francisco. (1991): "La formación del obrero en la Europa de entreguerras (1919-1939): las principales instituciones socialistas y las Internacionales Obreras de la Enseñanza”, en: Estudia Histórica. Historia Contemporánea, IX, p. 47.

${ }^{17} \mathrm{La}$ iniciativa de crear un organismo internacional de maestros se planteó en los congresos nacionales de Tours y Bolonia (1919), pero su conformación y desarrollo se realizó en seis congresos: Burdeos (agosto 1920), París (agosto 1922), Bruselas (1924), Viena (agosto 1926), Leipzig (abril 1928) y el último que debía realizarse en Amberes (1930): Algunas fuentes toman el de Burdeos como el primero y otros el de París. DE LUIS MARTÍN, 1991, p. 44.

${ }^{18}$ En la reunión celebrada en Berna en 1919 se intentó resucitar la II Internacional socialdemócrata que existía desde el siglo XIX, convocando a todos los Comités Nacionales, quienes mostraron diferentes posturas sobre el apoyo o no que se debía dar a la Revolución Rusa. En esta reunión se designó un Comité Socialista Internacional que radicaría en la ciudad de Amsterdam, el cual celebró algunas reuniones en un intento por unificar la postura socialista, la cual empero terminó por fragmentarse. Se fundó una nueva II Internacional reuniéndose por primera vez en Ginebra en 1920. Sin embargo entre la Conferencia de Berna y la de Ginebra se fue desarrollando una nueva corriente "centrista" que más tarde se llamó Internacional de Viena o Segunda y media, que oscilaba entre la II y la III Internacional. Así para 1922 existían Tres Internacionales: la de Amsterdam, la de Moscú y la de Viena, las cuales intentaron unirse en la Conferencia de Berlín. Dado el fracaso de esta iniciativa, se realizó un nuevo Congreso celebrado en Hamburgo en 1923, en el cual se unificarían las corrientes socialistas con la creación de la Internacional Obrera Socialista (IOS) que tendría por secretario a Adler. DEL ROSAL, Amaro. (1963): Los Congresos Obreros Internacionales en el siglo XX. De 1900 a 1950. Editorial Grijalbo, México, pp. 137-140, 144$150,153,158,165$. 
(provenientes en su mayoría de las secciones de Bélgica y España) como una minoría dentro de la organización ${ }^{19}$.

Según su propia definición se trataba de una organización "proletaria, revolucionaria y además unitaria”, que buscaba alcanzar la unidad de los trabajadores de la enseñanza para combatir contra las fuerzas reaccionarias de la educación (clericales y burguesía laica) y todos los peligros del imperialismo y el fascismo internacional. Para esta batalla, además de las reuniones señaladas, la organización tenía un Boletín publicado mensualmente en francés, alemán, inglés y español, el cual era redactado para los "camaradas" y simpatizantes que buscaban coordinar y controlar la lucha de organizaciones nacionales afiliadas mediante la elaboración de estrategias de acción. Para mantener la representatividad de un grupo tan heterogéneo debían de reunirse en un Congreso Internacional, órgano máximo que debía reunirse anualmente con todos los delegados de las secciones nacionales para acordar los temas más relevantes y de quien dependía la elección de un comité ejecutivo compuesto por 11 miembros que se reuniría una o dos veces al año y el secretariado general (compuesto de tres personas) encargado de implementar las decisiones tomadas por el Comité Ejecutivo y publicar el Boletín ${ }^{20}$.

Pocos meses después de realizarse el Congreso de la IMA en Buenos Aires se reunían en Leipzig (agosto 1928) los delegados de la ITE, quienes una vez terminada su reunión realizaron unas Jornadas Pedagógicas en las que tras la crítica a la escuela capitalista se formuló un nuevo aparato educativo de una escuela de clase, racional y humana destinada a formar a los niños obreros ${ }^{21}$. Pensado como un manual que sirviera para dar sustento

${ }^{19}$ El debate más importante surgió en torno al dilema entre educación de clase o educación racionalista, intentando solucionar las diferencias al llegar al acuerdo de que no existía oposición entre ambos puntos de vista: la escuela proletaria se daría dentro del período revolucionario e inmediato posterior mientras que la escuela racionalista surgiría después cuando existiera una sociedad sin clases. Hasta que la revolución llegara, los maestros debían acercar la escuela al proletariado, incluyéndolo en los consejos de padres y de maestros e intentando por todos los medios neutralizar la enseñanza burguesa. DE LUIS MARTÍN, 1991, p 48.

${ }^{20}$ Boletín de la ITE, año 5, núm.1, febrero 1927, pp.54-56.

${ }^{21}$ En las Jornadas se trataron los siguientes temas: fin de la educación, escuela y sociedad, problemas y métodos, disciplina escolar, situación material moral y jurídica del niño proletario. Sobre el tema de la situación material y jurídica del niño proletario hubo una completa unanimidad entre los participantes, mientras que al definir los fines de la educación encontró mayor divergencia puesto que mientras algunos se adscribían completamente al materialismo histórico, otros pedagogos provenientes de la socialdemocracia respetaban la independencia del proceso educativo de las relaciones de clase. Menos atención tuvieron los temas de organización escolar y a los programas y métodos, pero era evidente que existían divergencias entre los puntos de vista entre aquellos que defendían que la infancia proletaria debía adquirir conciencia de su medio y quienes defendían que era un error hacer vivir a los niños las experiencias de los adultos.

Así, el prólogo concluye que si bien es cierto que la verdadera solución de la enseñanza deviene del advenimiento del socialismo, no es cierto que los pedagogos socialistas no tengan nada que hacer en el régimen capitalista. PEDAGOGÍA PROLETARIA. INFORMES, TESIS Y DEBATES DE LAS JORNADAS PEDAGÓGICAS DE LEIPZIG, (1928): París, ediciones de la ITE. pp.5- 10. 
teórico y práctico con el fin de difundir su ideario a escala mundial, el libro sirvió para expandirse dentro y fuera de Europa, estableciendo nuevas secciones en Asia y América Latina, lugares donde la implantación fue reducida a veces hasta convertirse en una representación individual ${ }^{22}$.

Es evidente que la existencia de ambas organizaciones implicaba una disputa teórica sobre el predominio de la lucha de clases en la educación, pero también práctica, por sumar a sus filas los gremios de maestros. Por ello, no es casual que la revista peruana Amauta dirigida por José Carlos Mariátegui $^{23}$, reproduzca un mensaje que la ITE envía a los maestros que se reunieron en Córdoba para la Primera Convención Nacional de Maestros argentinos en 1929. Dirigido a los "camaradas", el mensaje da muestras de la permanente tensión que existía entre ambas organizaciones: mientras la IMA afirmaba su "solidaridad indestructible" y su "alianza moral" con el ITE, éste advertía a los maestros ahí reunidos para crear una alianza entre ambas organizaciones era necesario que la IMA respondiera tanto en sus fines como en sus medios a la lucha de clases $^{24}$.

22 DE LUIS MARTÍN. (1991): pp.49-50. La expansión empero inicia un período de crisis durante la década de 1930 cuando la Internacional Sindical Roja iba rumbo a su desaparición, mientras los Frentes Populares y la supremacía de las organizaciones sindicales adscritas al socialismo tendrían un nuevo auge. Pese a la crisis, la vida de la ITE se prolongaría hasta el estallido de la II Guerra Mundial cuando la ITE desaparecería definitivamente.

23 Amauta era una publicación dedicada al arte y la política que fundó en 1926 el intelectual José Carlos Mariátegui, quien para ese año había roto políticamente con el líder aprista Víctor Raúl Haya de la Torre para fundar el Partido Socialista Peruano y en 1929 la Confederación General de Trabajadores del Perú. Sus planteamientos fueron llevados al Congreso Sindical Latinoamericano celebrado en Montevideo (mayo) donde se funda la Confederación Sindical Latino Americana y la Conferencia Comunista Latinoamericana reunida en Buenos Aires en junio de 1929. Sin embargo, no se logró establecer un acuerdo debido a que los planteamientos de Mariátegui fueron cuestionados por el buró político de la Internacional en Sudamérica. Para ver un estudio minucioso sobre la publicación y las redes intelectuales que establece Mariátegui remitimos a: BEIGEL, Fernanda. (2006): La epopeya de una generación y una revista: las redes editoriales de José Carlos Mariátegui en América Latina. Buenos Aires, Editorial Biblos y BEIGEL Fernanda. (2003): El itinerario y la brújula. el vanguardismo estético-político de José Carlos Mariátegui, Buenos Aires, Editorial Biblos.

${ }^{24}$ Amauta, núm. 22, abril 1929, pp. 76-80. En el mismo número, se publica un artículo redactado por la IMA para informar sobre las persecuciones que vivían los maestros chilenos por parte del gobierno, de los cuales 30 fueron declarados conspiradores y confinados a la isla de más afuera (en el pacífico), mientras otros 106 fueron destituidos de su cargo, como anteriormente lo habían sido otros tantos. En solidaridad con ellos y sus familias se reunió una colecta de 2,297.30 pesos entre los asociados de Argentina, Paraguay, Perú, Uruguay, España y Francia Amauta, núm. 22, abril 1929, pp. 80-82. 


\section{Maestros y pedagogía revolucionaria}

En el año de 1929 la tensión va a hacerse más evidente cuando en el Congreso Nacional celebrado en Montevideo en mayo de1929, se funda la Confederación Sindical Latino Americana (CSLA), organismo que nace bajo la influencia de la III Internacional ${ }^{25}$. Por ello no es de extrañar que desde su creación se planteara como enemigos a las dos organizaciones "amarillas" y "colaboracionistas" del Imperialismo: la Internacional de Amsterdam y la Confederación Obrera Panamericana del Trabajo (COPA), a las que acusan de haber desviado a las masas del verdadero camino revolucionario, al constituir organizaciones reformistas en coalición con la burguesía económica y gobiernos dictatoriales.

A nivel regional la CSLA disputara por la legitimidad de la IMA publicando en el Trabajador Latino Americano, órgano de difusión dirigido por Juan Solari, algunos artículos propios que buscaban desprestigiar a su par latinoamericano, reproduciendo además en sus páginas otras críticas realizados por la ITE $^{26}$. Además, la CSLA se plantea como estrategia tomar el control de la organización magisterial latinoamericana, éxito que no había podido obtener en la Primera Convención debido a que sus propuestas quedaron siempre en franca minoría. Para evitar que cayera en el "amarillismo", proponen sistemáticamente señalar en todos los temas a tratar, el contraste entre la deplorable educación de los países capitalistas frente al progreso en la Unión Soviética. Esta tarea implicaba un choque

${ }^{25}$ Los delegados de los sindicatos de clases de Argentina, Brasil, Colombia, Cuba, México, Uruguay, Chile y Ecuador al encontrarse en Moscú (en ocasión del X aniversario de la revolución de octubre) en la Internacional Sindical Roja el 11 de diciembre de 1927 tras cuestionar que la Federación Pan Americana de Trabajadores es un instrumento del imperialismo norteamericano, deciden "unificar el movimiento sindical en estrecha relación con el movimiento obrero internacional por la constitución de una internacional única de clase". Para ello, se nombra un secretariado provisional encargado invitar a los sindicatos para conformar un secretariado sindical latinoamericano en un Congreso a realizarse en Montevideo en mayo de 1929. En la reunión de Moscú, intervino A. Losovosky, secretario general de la Internacional Sindical Roja, a solicitud de los delegados latinoamericanos con el fin de que realizara un informe general de los movimientos obreros de la región. Tras la exposición del informe y pese al protagonismo que tuvo Losovosky en los debates del encuentro, aclara que la futura Confederación Sindical Latino Americana no debe adherir a la Internacional Sindical Roja, pero debe establecer relaciones con ella "a fin de utilizar su experiencia internacional en el movimiento sindical". En el Congreso de Montevideo, se envió de representante de la ISR al camarada Mayer, quien además de llevar el saludo fraternal, explica las tareas y métodos utilizados por la ISR a fin de que sirva de ejemplo. Dada esta proximidad, la CSLA exhorta a sus miembros adherir a las secciones nacionales de la Sindical Roja -o que los creen en caso de no existir en su país-, solicitando también el apoyo material al SRI por medio de suscripciones, colectas, etc. SINDICALISMO: resoluciones de la Confederación Sindical Latino Americana (1928), s.n., pp. 5-32 y 289.

${ }^{26}$ El trabajador, año II, núm. 17-18, junio y julio de 1929, pp. 30-31. 
inevitable con los delegados burgueses de múltiples tendencias (reaccionarios liberales, reformistas, anarco- cristianos, anarco y social fascistas) pero era considerada indispensable para asegurar que los maestros de América Latina determinaran el fracaso de la IMA y con ello de "agentes del imperialismo yanqui" la F.I.A.I. (World Federation of Education Association), quien enviaría delegados a la reunión ${ }^{27}$.

Según lo previsto, se reunió en febrero de 1930 la Segunda Convención Americana de Maestros, con un temario un poco más acotado en su número pero no en su tono político. Los ejes recaían en la formación cultural-moral y la problemática material de los maestros, las condiciones políticas del continente (avance del imperialismo y de las dictaduras) y los deseos de estimular el ideal de solidaridad-justicia-paz en el continente, así como en las cuestiones relativas a la educación del niño (pedagógicas y sobre los derechos del niño). La reunión tuvo una mejor acogida en el ambiente universitario uruguayo, el cual recibió con entusiasmo a los delegados del continente, a los extranjeros que como el profesor español Rodolfo Llopis, y el ex profesor de Berlín José Nicolai y a quienes como Miguel de Unamuno, enviaron sólo sus saludos para darle mayor legitimidad a la organización ${ }^{28}$.

Al no haber podido cooptar la organización durante el evento, el Trabajador publicó una última y tajante afirmación: la IMA es una organización reaccionaria, enemiga del proletariado revolucionario latinoamericano y aliado del imperialismo yanqui. A esta conclusión llegaba tras informar detalladamente la composición social de la convención y los acuerdos realizados. Para ellos era evidente en rasgos generales la numerosa participación de representantes de gobierno (directores de instrucción pública y otros funcionarios menores), así como la presencia de la delegación de Uruguay y Argentina ${ }^{29}$.

${ }_{27}$ El trabajador, año II, núm. 26-27, diciembre de 1929, pp.15-17.

${ }^{28}$ Unamuno afirma en su mensaje que han realizado un paso muy importante al constituir una "Internacional de Maestros" para replicar a los dictadores e imperialistas que intentan sobreponer la patria sobre otros principios como el de la libertad, la verdad y la justicia. Tras felicitarlos les pide solamente que tenga cuidado con el experimentalismo pedagógico norteamericano "que quita toda el alma a la enseñanza, que es ante todo arte y arte poética". Citado en: MARTÍNEZ TRUCCO. (2004): pp.86-87.

${ }^{29}$ Consideraban funcionarios al español Rodolfo Llopis y el uruguayo Emilio Furgoni (a quienes califican de traidores y esperan sean expulsados de la ITE). La delegación argentina compuesta por diferentes vertientes de anarquistas, la del Paraguay "castrada" por el tirano en el gobierno, y la del Brasil la cual se limitó a enviar como observadores a un grupo aristocrático para que se escogiera a Río como siguiente sede de la III Convención. Por América Central sólo se presentó Miguel Morazán, Ministro de Instrucción Pública de Honduras, mientras El Salvador envió credenciales para su representación al argentino Julio Barcos, a quien dedicaron varias frases para desprestigiarlo, calificándolo como "anarco-irygoyenista" porque es un "ex revolucionario romántico, transformado según su propia definición, en revolucionario 
Tras "desenmascarar" a los delegados la crítica siguió con las propuestas, de las cuales donde mayor debate hubo fueron las relativas a la creación de la Universidad de la Cultura Americana y a la declaración del avance del imperialismo y de las dictaduras en América Latina ${ }^{30}$. El proyecto universitario fue atacado por ser un instituto destinado a la educación de las minorías privilegiadas, mientras que ellos defendían la idea de crear escuelas para la nueva educación proletaria para los niños de la clase obrera y campesina, sostenidas por los sindicatos de clase, las ligas campesinas, los bloques obreros, escuelas en las cuales participarían los profesores "revolucionarios" desocupados o expulsados por el gobierno. Esta divergencia se hizo más notoria al tratar el tema imperialista dado que partiendo de la suscripción de la teoría leninista (imperialismo, última fase del capitalismo) declaraban nula la acción de la IMA mientras ésta no aceptase adherirse a la Liga Mundial contra el Imperialismo (con sede en Berlín) y a nivel local, a las ligas antiimperialistas de los respectivos países ${ }^{31}$.

\section{Con palabras muy similares, la ITE declaraba enemigo a la IMA porque} los pequeños burgueses que lo dirigen aunque reconocen la existencia de la lucha de clases, consideran como dogmático o sectario el estudio de los problemas planteados desde este punto de vista. Por ello, insistían en que los maestros de América Latina debían organizarse en sindicatos de clase

constructivo" a cambio de su traición al proletariado por alcanzar el puesto de inspector de escuelas que ha recibido del gobierno de Yrigoyen. El trabajador, año II núm. 30, marzo-abril 1930, pp. 8-15.

${ }^{30} \mathrm{Nad}$ mencionan sobre la participación uruguaya en la cual estuvo el intelectual Vaz Ferreira quien presentó su proyecto pedagógico de los parques escolares, complejos situados en las afueras de la ciudad donde los niños tendrían espacios libres y servicios comunes (bibliotecas, salas de conferencias, materiales de enseñanza, etc.,) La propuesta fue aprobada por unanimidad por la Segunda Convención pero el Consejo de Enseñanza Primaria de Uruguay se opuso y lo rechazó. VAZ FERREIRA, Carlos. Lógica viva. (1979): Moral para intelectuales. (Prólogo de Manuel Claps). Caracas, Biblioteca Ayacucho, p. 40.

31 El trabajador, año II núm. 30, marzo-abril 1930, pp. 8-15. La Liga Antiimperialista de las Américas (LADLA) se fundó en la ciudad de México entre fines de 1924 y principios de 1925 y constituyó uno de los intentos más ambiciosos del comunismo internacional por impulsar la revolución en el continente americano una vez que se vieron agotados los efectos en Europa y que el movimiento en China se inclinara hacia un fervor nacionalista y anti colonial. Su existencia fue real, expandiéndose a quince países americanos incluyendo los Estados Unidos, al ofrecer un espacio que vinculaba las expresiones antiimperialistas de la burguesía liberal con aquellas más radicales de comunistas, siempre y cuando las clases medias se plegaran a los reclamos y la dirección de obreros y campesino. Como experiencia se agotó cuando el frentismo fue reemplazado a fines de la década de 1920 por la lucha clase contra clase, fundiéndose en los frentes populares que surgieron en la región promediando los años treinta. KERSFFELD, Daniel. (2006-2007) :"tensiones y conflictos en los orígenes del comunismo latinoamericano: las secciones de la Liga Antiimperialista de las Américas" en: Estudios interdisciplinarios de América Latina y el Caribe, Facultad de Humanidades Lester y Sally Entin, vol. 18:2. Consultado en: http://www1.tau.ac.il/eial/index.php?option=com_ content\&task $=$ view \&id $=815 \&$ Itemid $=314$ 
y entrar en relación con la sección uruguaya para adherirse al ITE ${ }^{32}$. Lejos habían quedado los intentos de acercamiento que se habían desplegado desde la primera convención en 1928 hasta los saludos fraternales de la federación norteamericana y del intelectual francés Henry Barbusse, que reprodujeron en los números previos ${ }^{33}$.

A partir de esta formal ruptura, la IMA reconstruiría ante los maestros su imagen a través de la publicación Liberación, portavoz mensual que venía a sustituir el antiguo Boletín para transformarse en una "revista pedagógica, gremial y doctrinaria" "34. En ella, se hacía un llamado regular a los maestros para que se suscribieran en cuanto éste pretendía ser una guía de estudio y el portavoz de las actividades de la IMA. También estaba pensado para los trabajadores, a quienes afirmaban "les interesa" estar informados de lo que se hace en el mundo "por la educación de vuestros hijos". Es evidente que el trabajador intelectual tenía un papel más relevante que el manual en las páginas del Boletín, donde en sus portadas aparecen los grandes maestros que sirven de ejemplo: el español Miguel de Unamuno, el francés Adolphe Ferriére, F. Bakulé, el cubano Enrique José Varona y el colombiano Agustín Nieto Caballero ${ }^{35}$.

Junto a esta figura casi mítica del maestro se ubicaba la del niño, a la cual se dedica toda la atención tanto de sus "intereses como de sus derechos". En virtud de ello, es interesante rescatar cómo se construye esta imagen en las apreciaciones de los asistentes a la Segunda Convención. Entre

${ }^{32}$ Boletín de la ITE, año 4 núm. 3, junio-julio 1930, pp.14-16.

${ }^{33}$ Boletín de la ITE, año 4 numero 1 enero febrero 1930 pp. 1-6. el Boletín de la ITE publicó con agrado el "saludo fraternal" que extendieron por su intermedio los maestros de EUA a los compañeros de América Latina. En él, se hace un llamado a los pueblos latinoamericanos para que se enfrenten "al águila americana" por ser un "buitre" que busca fagocitarse a las masas obreras de todos los países, como dan muestra las numerosas historias de "pillaje, asesinato y explotación". En el mismo número se publicaba el mensaje del intelectual francés Henri Barbusse, a los maestros de América Latina reunidos en Montevideo. En él, llama a los maestros -como directores espirituales de las acciones sociales del continente-, a enfrentar el avance del imperialismo norteamericano y para ello es necesario combatir junto a otros intelectuales y a las clases obreras en una "unión orgánica" sin la cual los intelectuales lucharían solitarios haciendo "demagogia revolucionaria". Por ello, finaliza afirmando que es indispensable enrolarse en esta causa universal contra los "parásitos sociales" del capitalismo y no ver el conflicto como la expresión de una lucha entre dos culturas o razas.

${ }^{34}$ Del Boletín sólo sabemos según los datos que se mencionan en las actas de la II Convención que apareció con regularidad 13 números, pero asumen que desgraciadamente la publicación no tuvo muchos lectores. Liberación, año I, núm. 1-2, junio-julio de 1930, pp. 22-23.

35 La alianza entre trabajadores intelectuales y manuales implicaba que aun reconociendo sus diferencias, ambos debían de apoyarse en busca del fin común, la emancipación económica y la fusión de clases en América. Por ello desde la Primera Convención se recomendaba la organización de comisiones mixtas de maestros y obreros. RESOLUCIONES, enero 1928, p. 1815. 
los oradores que abren el evento se encontraba Julio Barcos, quien había pertenecido en la década anterior a la Liga de Educación Racionalista, la cual defendió la idea que la humanidad se encuentra en un progreso infinito y que para solucionar las desigualdades e injusticias debe transformarse la esencia humana, desde la infancia a través de la educación influenciada por la filosofía positiva (la verdad demostrada y aceptada) fuera de todo dogma religiosos y siguiendo como modelo la pedagogía moderna ${ }^{36}$. Por ello, Barcos era reconocido como un representante destacado dentro del anarquismo del grupo racionalista que mantuvo relación con la Liga Internacional para la Educación Racionalista de la Infancia que había creado el español Francisco Ferrer i Guardia en $1906^{37}$. Los racionalistas compartían la convicción de que el niño y por ende la infancia, eran "la esperanza" de un mundo distinto en un futuro próximo y de toda la especie humana, pero para ello era necesario transformar la educación para que este actor político se formara sin dogmatismos ${ }^{38}$.

A fines de la década de los veintes, el cuestionamiento sobre el dogmatismo se renovaba al agregar al tradicional cuestionamiento de la educación religiosa, otra experiencia como la educación soviética. El español Rodolfo Llopis se explayara sobre este punto al cuestionar la educación que se estaba llevando a cabo en Europa, incluyendo en Rusia. En este sentido, al dar su impresión sobre su estancia en aquel país, recuerda que cuestionó a los "camaradas" la manera dogmática en que se estaba educando a los niños con el fin de crear una organización política infantil. En su defensa éstos le contestaron que la revolución había costado demasiado y era necesario salvarla a toda costa, incluso si esto implicaba tener que "apoderarse del alma de los niños".

${ }^{36}$ Según la "filosofía positiva", los individuos serían capaces de "vivir en la verdadera sociedad del futuro", si es que tienen conocimientos adecuados para acelerar y no retardar o detener la evolución. Boletín de la Liga de Educación Racionalista año 1, núm. 3, enero 1915, p. 6 y año 1 núm. 6, mayo 1915, pp. 1-2.

${ }^{37}$ El objetivo de esta organización era difundir un método propio adaptado a las necesidades psicológicas del niño a través de la elaboración de un conjunto de textos y la instrucción científica y racional que excluyera las nociones místicas o sobrenaturales. Concebida como una red de solidaridad de todos aquellos que buscaba educar a la infancia en la verdad y la justicia, para lograr generaciones "aptas para la emancipación religiosa, política y económica", la Liga llegó a expandirse internacionalmente contando con numerosos miembros adheridos y muchos simpatizantes, lo cual explica las expresiones de solidaridad y protesta tras el asesinato de Ferrer en 1909. Ver, CAMBRA BASSOLS, J. d. (1981): Anarquismo y positivismo: el caso Ferrer. Madrid, Centro de Investigaciones Sociológicas, p. 54.

${ }^{38}$ Los niños eran percibidos como el motor de cambio social para alcanzar la sociedad ideal del futuro porque la infancia es considerada la etapa de la vida humana más valiosa por la antigua fe en la bondad natural del hombre recogida de la Ilustración por el anarquismo. Por ello y siguiendo las ideas de Paul Robin, la escuela ideal es aquella en que el niño no sea dominado por un adulto sino que eduque con la "libertad como fundamento moral", haciendo del niño un sujeto activo -y responsable- de su propia educación. MAYOL, A. (1978): Boletin de la "Escuela Moderna". Barcelona, Tusquets. 
El ampliar el sentido de lo dogmático para incluir en él no sólo a la educación impartida por la Iglesia, sirvió nuevamente para marcar las diferencias "doctrinarias" entre el grupo de la minoría (identificado como clasista) que buscaba definir a la IMA como una organización de clase y la mayoría (identificado como idealista) que se atribuía tareas de "carácter político social", siempre y cuando éstas estuvieran determinadas por "ideas de liberación humana" que nuevamente encontraban su legitimación en promover "el mayor bien material y espiritual del niño".

Las diferencias políticas se repetirían, haciendo irreconciliable las propuestas educativas, motivo por el cual las mesas terminaron con dos despachos por la falta de acuerdo ${ }^{39}$. En otros casos, la solución fue posponer el debate para la siguiente convención a realizarse en Río de Janeiro en enero de 1932, solución similar que se presentó al debatir el tema del privilegio de las minorías en la Educación. Pese a la notoria desventaja con la que contó la minoría y al evidente distanciamiento que esto implicaba con respecto a la ITE, es interesante señalar que el evento fue considerado por algunos medios oficiales como una reunión de "comunistas", crítica que fue refutada en varias ocasiones ${ }^{40}$.

Pese a las críticas y debates, la Segunda Convención definió las normas de funcionamiento con miras a consolidar y expandir su propia internacional, la del magisterio americano, organización continental que se concretaría mediante tres figuras: La Convención, que se reunirían cada dos años o extraordinariamente cada vez que se requiriera por dos tercios de sus partes y en la cual participarían dos delegados por institución adherida (que estuvieran al corriente con sus pagos); el Consejo americano (integrado por un delegado por cada país adherido y el Secretario americano que lo presidirá una vez

39 Específicamente al discutirse sobre la formación de los maestros, la mayoría propone seleccionar mejor al personal mientras la minoría defiende suprimir la escuela normal y reemplazarla por un instituto de tipo universitario, al que los futuros maestros llegarían al finalizar la Segunda enseñanza. Al tratar el tema la escuela y el maestro ante la unión de los pueblos americanos: modos de estimular la paz, la solidaridad y la justicia (en el cual se incluía el tema, lucha contra los imperialismos), la mayoría sostuvo que la escuela es eficiente para preparar la paz y unión de los pueblos y en cuanto a los imperialismo sólo reconoció que se apoderan de naciones débiles. En cambio la minoría desde un criterio materialista, defendió la revolución como principio para alcanzar la paz y dentro de esta lucha las escuelas sólo servirán cuando los organismos magisteriales respondan por completo "a una sola clase o más bien a un solo Partido". Liberación, año 1, núm. 1-2, julio-agosto, 1930. El subrayado es nuestro.

${ }^{40}$ Liberación, año I, núm. 3, septiembre de 1930, pp. 4-6. La IMA acusa a los delegados de Bolivia de conspirar contra la organización, respondiendo a las órdenes del gobierno boliviano en Argentina el cual tanto en la I Convención como en la II obligó a sus delegados a retirarse con excusas varias para posteriormente utilizar esto como excusa para atacar al IMA y a sus reuniones por su "ambiente comunista". Liberación, año I, núm. 3, septiembre de 1930, pp. 4-7. En otro número se reprodujo una carta del representante boliviano Donoso, quien aseguraba que la IMA no era una entidad comunista. Liberación, año I, núm. 5-6, noviembre-diciembre 1930, pp. 19-21. 
que la mayoría de la Convención lo haya elegido (pudiendo ser reelectos en la siguiente reunión al igual que los miembros del Consejo). Para facilitar la labor del Secretario y el Consejo, que residía en la ciudad de Buenos Aires, se funda la Oficina Pedagógica Americana la cual debe reunir y difundir toda la información sobre el movimiento educativo en la región y la secretaría auxiliar en Centroamérica, la cual quedará conformada por un representante de cada país para favorecer la propaganda y organización de federaciones magisteriales que se adhirieran a la IMA. Para facilitar aún más la organización en otros países donde el magisterio no había respondido se creó el "grupos de amigos de la IMA", en los cuales podían incluirse obreros y maestros que no estaban incorporados a federaciones adheridas a la Internacional ${ }^{41}$.

El siguiente número de Liberación se nutrió aún de los sucesos de la II convención, ampliando la información sobre el proyecto de crear una Universidad de la Cultura Americana presentado por Julio Barcos, Atilio E. Torrassa y Enrique Rodríguez Fabregat. Partiendo de la labor de los "trabajadores intelectuales de América", se pensaba que ésta serviría para hacer surgir una "cultura propia" mediante una serie de acciones: la docencia libre, el intercambio de docentes en el continente, organizar (vía canje o venta) un mercado editorial americano de libros y revistas, formar bibliotecas de autores americanos en cada sección nacional (con la contribución de las otras secciones), suministrar a la oficina pedagógica americana de la IMA la información sobre el movimiento educativo de su país (estadísticas, legislaciones, reformas educativas, etc.), encomendar a especialistas el estudio de la unidad del idioma y la reforma de la ortografía, así como la preparación de una asignatura de Historia Americana ${ }^{42}$.

${ }^{41}$ Sólo se conformaron dos grupos de amigos: en Argentina (La Plata y Córdoba) y en Perú (Cuzco y Chiclayo). A su vez las Federaciones y sociedades adheridas durante este tiempo fueron las siguientes: Argentina. Confederación Argentina del Magisterio (Tucumán), Federación Provincial del Magisterio de Santa Fe (Rosario). Bolivia. Liga Nacional del Magisterio (La Paz). Chile. Asociación General de Profesores de Chile (Santiago). Ecuador. Asamblea de Profesores (Quito). El Salvador (Asociación de Maestros de El Salvador (San Salvador). Guatemala. Sindicato de Maestros de Educación (Guatemala). Honduras. Sociedad Magisterial Nacional (Tegucigalpa). México. Liga Nacional de Maestros (México D.F.). Paraguay. Federación del Magisterio Paraguayo (Asunción). Uruguay. Federación Magisterial Uruguaya y Asociación de maestros José Pedro Varela (Montevideo). En las actas de la II Convención se mencionan estas delegaciones y se agregan en el caso de Argentina otras organizaciones de provincia: Círculo docente de Catamarca, Asociación El magisterio de La Rioja y el Centro Cultural del maestro de La Banda (Santiago de Estero).

42 Liberación, año I, núm. 3, septiembre 1930, p. 1-2. La idea de crear esta Universidad había sido planteada por Barcos anteriormente al realizar un homenaje tras la muerte de José Ingenieros, cuando afirmaba que la mejor manera de honrarlo sería fundar una universidad popular (o una escuela social), proyecto que comenzaría en la capital y luego en las provincias. Poco después la iniciativa fue pospuesta por Barcos debido a que prefirió abandonar el proyecto ante la posibilidad de que el "sectarismo político" (haciendo referencia la Liga Antiimperialista Sección Argentina) especulara con el nombre de Ingenieros, olvidando que éste se había segado en vida a empequeñecer la revolución con bandos políticos. Claridad, año 6, núm. 145, 25 de octubre de 1927. 
Sin embargo, al replantearse la propuesta ante la Segunda Convención mantendría difusamente un tono popular pero se concentraría en las acciones que fomentan el acercamiento de los intelectuales. Pese a esto, Barcos aseguró después que este proyecto hubiera colmado la alegría a José Ingenieros al buscar diferenciarse de la universidad "que expide títulos profesionales sin interesarse ni por la investigación de la ciencia pura ni por la difusión de la cultura general en el pueblo que la costea". Frente a esta esterilidad social que prepara "mandarines para la clase dirigente" se plantea en cambio, "el magisterio de la intelectualidad libre" $"$.

En los siguientes números, no se volvió a mencionar nada al respecto. Las páginas de Liberación se concentraron en mantener informados a sus lectores mediante tres secciones: movimiento educativo, el maestro en acción y bibliografía. Para nutrirlas, la información debía de ser proporcionada por las entidades adherentes pero que parece quedó en manos del Secretario Americano, quien tuvo que recolectarla de diversos periódicos dado el fracasado intento de que los lectores colaboraran con el envío ${ }^{44}$.

La primera sección se dedicaba a presentar "hechos, organismos y estadísticas" para los países latinoamericanos, información sobre congresos y conferencias internacionales sobre educación. Estas descripciones se hacían más puntuales en la siguiente sección "el maestro en acción”, donde se mencionaba con detalle los atropellos que vivían los maestros por parte del gobierno, así como cuestiones respecto al salario y la creación de organizaciones. El carácter local y anecdótico sólo era superado en la sección dedicada a la bibliografía de libros, folletos y revistas que se recibían de varios países sobre temas educativos: memorias de organizaciones, libros de texto de alguna asignatura, avances de sistemas novedosos europeos. De ellos, pocos libros tenían un comentarista siendo la mayoría una descripción breve de los datos editoriales y del contenido, mientras que las revistas eran comentadas por el Secretario Americano de la IMA. Cabe señalar que en el caso de las revistas, su temática abarcaba tanto aspectos relativos a la educación y a la infancia, como a cultura en general, posiblemente porque eran recibidas mediante canje $\mathrm{e}^{45}$.

${ }^{43}$ BARCOS, Julio. (1931): Política para intelectuales. Buenos Aires, s.n. pp. 175-179.

${ }^{44}$ Liberación, año II, p. 26. Enero-febrero de 1931, núm. 7-8.

${ }^{45}$ Entre los libros comentados se encontraba: Figueira Gastón, Para los niños de América (1928), Dura Horacio, la educación moral del niño en la escuela primaria (1929), Ognev N, el diario de Costia Riabsten (1930), Lynch A. J, el trabajo individual en la escuela, según el plan Dalton (1930), Ponce Aníbal, la evolución de la inteligencia infantil (1930). Entre las revistas de canje recibían: Educación, órgano del Ministerio de Instrucción Pública y Bellas Artes (Quito, Ecuador), Patria (San Salvador), Baixeras, (Barcelona), el altiplano (Oruro, Bolivia), Repertorio Americano (Costa Rica), Alas (Montevideo), La Colmena (Madrid).

${ }^{46}$ A Mariátegui se lo honra como el sucesor de Manuel González Prada por haber sido un "ideólogo proletario" al servicio de los trabajadores desde un prisma materialista de la III Internacional, identificación que es completada con una imagen suya -sin autor-, un listado de sus obras y la reproducción de una autobiografía. Liberación, año I, núm. 3, septiembre 1930, pp. 12-13. 
A esta información de proyección internacional se agregaba otra que informaba sobre personajes relevantes del movimiento intelectual latinoamericano como Enrique José Varona y José Carlos Mariátegui ${ }^{46}$, así como del movimiento educativo europeo. En este caso, es sintomático que se transcriban las entrevistas realizadas a Rodolfo Llopis y Ferdinand Buisson, quienes habían sido invitados por la IMA a participar en una serie de eventos como la II Convención, así como de Adolfo Ferriére, quien disertó en Buenos Aires y La Plata sobre la Educación nueva y la escuela activa, defendiendo la labor realizada por el Instituto de Ciencias de la Educación y la Oficina Internacional de Educación (ambas con sede en Ginebra) ${ }^{47}$. Ambas referencias marcaban el acercamiento hacia una propuesta educativa más experimental y menos teórica, así como a un organismo internacional que, dependiente de la Sociedad de las Naciones, se encontraba distante de los mencionados anteriormente ${ }^{48 .}$

${ }^{47}$ En las conferencias transcriptas se desarrolla con detalle las ideas de esta corriente iniciada por el psicólogo Cléparde con la Escuela de Infantes en Ginebra (1912) y que tiene en la actualidad su fundamento en los estudios de psicología genética realizados por Jean Piaget, a la cual definen como "la ciencia del crecimiento del espíritu". Parte del fundamento que cada etapa histórica tiene la escuela que requiere según su evolución social, pero que en la actualidad esta se encuentra atrasada por completo puesto que su espíritu general es de la Edad Media y de la era napoleónica, dejando de lado el desarrollo industrial y científico de los últimos 50 años. Así, basándose en las demostraciones de la Psicología Genética afirman que lo principal es el desarrollo de la vida interior del niño, el cual se alcanza a través de la libertad individual y la autoridad social mediante la "autoformación funcional del niño" - siguiendo las ideas de John Dewey y María Montessori. Para este tipo de escuela es necesario preparar maestros expertos en los progresos de la ciencia, transformación sin la cual, la reforma educativa quedará en letra muerta. Por todo esto termina instando a que se realizan estudios comparativos utilizando el método de Piaget en las escuelas de Argentina. Liberación, año I, núm. 3, septiembre 1930, pp. 14-21.

${ }^{48}$ Fundada en Ginebra en 1925 como organización no gubernamental y privada, la OIE se proponía recopilar la documentación relativa a la enseñanza, interesarse en la investigación científica-educativa y servir de enlace para aquellos interesados en el tema de la educación. Entre sus miembros fundadores se encuentran Edouard Claparéde, Pierre Bovet y Adolphe Ferriére, quienes habiendo recibido una donación de la fundación Rockefeller para el Instituto J. J. Rousseau se apresuraron a destinar una parte de este monto a la creación de dicha Oficina. El pedagogo Jean Piaget fue nombrado su director en 1929 cuando la OIE amplió su composición a los gobiernos debido a la falta de recursos económicos para sostenerse como órgano independiente, convirtiéndose en la primera organización intergubernamental en el ámbito de la educación. Su nombre permanece estrechamente vinculado al de esta organización, la cual dirigió por casi cuarenta años junto a Pedro Rosselló quien era vice-director de la Oficina. ROSELLÓ, Pedro. Nota histórica sobre la OIE (1934-1977). Consultado en http://www.ibe.unesco. org/fileadmin/user_upload/Publications/Institutional_Docs/rossello_nota_ historica_sp.pdf 


\section{CONCLUSIÓN}

Años más tarde el Magisterio Americano realizaría otros cuatro congresos en un contexto político marcado por la Segunda Guerra Mundial y el inicio de la Guerra Fría ${ }^{49}$. Posiblemente, los actores de esa trama enfocaron sus propuestas de un modo distinto, recayendo en el temor del fascismo el enemigo común, pero mantuvieron la preocupación por la enseñanza del niño, fomentando así la representación de la infancia como nuevo sujeto histórico.

Como hemos intentado mostrar, los actores sociales estudiados entablaron un debate sobre el sistema educativo más que sobre cuestiones pedagógicas. Se buscaba terminar de definir o modificar la relación impuesta entre la autoridad plena de los Estados liberales que se habían establecido en América Latina y la autoridad del maestro y de la escuela. Romper con el orden vertical y con la injerencia totalizadora de la educación en estos países era así de mayor importancia que debatir sobre cual corriente o método de vanguardia educativa sería implementado. La enseñanza nueva, científica y antidogmática como principio, implicaba una referencia tenue a las propuestas implementadas a Delacroy, Montessori, sirviendo para reafirmar la idea de que la atención debía de centrarse en el niño y el maestro.

Modificar el sistema educativo era visto como paso necesario para implementar las innovaciones pedagógicas. Por ello, los debates de los participantes de las dos convenciones que realizó IMA pese a sus diferencias, podrían inscribirse dentro de la corriente pedagógica "escolanovista" que durante el período de entreguerras se enfrentó a la corriente normalista tradicional que defendía la burocracia que dirigía el sistema escolar argentino. Pese a sus diferencias -que radicaban esencialmente en el sentido que otorgaban al trabajo como actividad escolar-, estos coincidían en algunos principios básicos de vanguardia (como la educación de la mujer, la coeducación, la

${ }^{49}$ En La Habana, Cuba, del 4 al 8 de septiembre de 1939, se realiza el Tercer Congreso de Maestros Americanos, en donde destacan los estudios sobre la conciencia internacional del magisterio.

Del 26 al 31 de diciembre, de 1943, en el Cuarto Congreso Americano de Maestros realizado en Santiago de Chile, se consolida la Organización Americana de Maestros, dando paso a la Confederación Americana del Magisterio (CAM). En mayo de 1946, en la ciudad de México se efectúa el V Congreso de la Confederación Americana del Magisterio. Estudia los problemas de la independencia nacional, del desarrollo económico y la preservación de la paz en los países de América. Examina también los problemas fundamentales de la democracia en América y su influencia en la educación; se pronuncia por una colaboración con la UNESCO. En Montevideo, Uruguay, en enero de 1957 se realiza el VI y último Congreso de la Confederación Americana del Magisterio, para dar paso a la creación la CEA, que agrupa a las organizaciones nacionales de trabajadores de la educación del continente americano que voluntariamente se adhieren, aceptan sus principios y objetivos y cumplen, en tiempo y forma, los requisitos de ingreso establecidos en los presentes estatutos. en http://www.ceasubsede.com.uy/historia.htm. 
laicidad, la libertad de expresión, la autonomía del niño, la participación de los docentes y el estímulo a la creatividad) ${ }^{50}$.

Recuperando la tesis de Juan Carlos Tedesco al analizar la formación del sistema educativo argentino a fines del siglo XIX, consideramos de gran importancia utilizar la variable política para el análisis de los fenómenos educativos, no para sobrevalorar o predeterminar los comportamientos de la educación a una actitud política, pero si "para entender las actitudes de los diferentes sectores sociales frente a la educación en el marco más correcto posible" 51 . Siguiendo la lógica de Julio Barcos, si los maestros no se elijen por su virtud, su moral y su capacidad científica por un consejo compuesto por padres de alumnos y pares del magisterio, la educación que se imparta dentro de las aulas seguirá siendo no revolucionaria al servir a los fines del statu quo y los intereses de una clase dominante en la que no sólo se encuentra la aristocracia económica sino la autoridad política del Estado.

Esta premisa nos ayudó a entender no sólo la búsqueda por organizar un gremio de maestros sino para detectar las semejanzas y diferencias en los debates que emprendieron las organizaciones señaladas. Compartían la convicción de que existe una Razón por la cual el proceso social es inevitable y positivo en cuanto siempre va en búsqueda de un cambio que

${ }^{50}$ Citado en PUIGGRÓS, Adriana. (2003): El lugar del saber: conflictos y alternativas entre educación, conocimiento y política. Buenos Aires, Galerna, pp.184-185. La corriente normalizadora predominante en la propuesta escolar normalista creía en el binomio sarmientiano de civilización y barbarie y se encontró influenciada por el higienismo. La corriente democrático-radical influenciada por Fröebel y la Escuela Superior de Enseñanza de España buscaron mejorar el sistema educativo impulsando la autogestión y centrando la atención en el niño. La corriente socialista, defendía el papel del Estado en la educación al tiempo que promovieron sociedades de educación y bibliotecas populares donde se difundieron ideas avanzadas de Comte, Marx, Darwin y los higienistas de la época. Los educadores anarquistas fueron anti estatistas y promovieron la creación de escuelas ligadas a mutuales, sindicatos obreros y grupos anarquistas. PUIGGRÓS, Adriana. (2006): Sujetos, disciplina y currículum en los orígenes del sistema educativo (1885-1916). Buenos Aires, Editorial Galerna.

${ }^{51}$ Como señala Tedesco para el caso argentino, el sistema educativo se expandió considerablemente no por seguir los requerimientos de una economía agro exportadora sino desvinculado de él, para sustentar necesidades políticas del régimen cuya estabilidad dependía de la necesidad de educar a las masas para seguir un modelo moderno-civilizatorio pero al mismo tiempo mantener la acción de las éites dirigentes en su capacidad de dirección. Por este motivo la educación que impartía o controlaba el estado tuvo en sus inicios un sentido enciclopedista (como formación de cultura general) y se concentró a través de la ley 1420 y la ley avellaneda (que imponían las nuevas reglas estatales a la educación primaria y universitaria), dado que no era necesario recursos humanos para puestos medios superiores a la mano de obra no especializada e inferiores al universitario de élite. No es extraño entonces que hacia 1916 cuando el radicalismo llega a la presidencia el aumento de los sectores medios cuestionaran el sistema educativo tradicional en su enfrentamiento con la oligarquía por democratizar las vías de acceso al poder. TEDEESCO. (1982): pp. 158-160. 
mejorare significativamente a toda la sociedad. Ambos pretenden facilitar el proceso de transformación histórica dando fin al capitalismo para llegar a un socialismo, etapa de progreso social donde las diferencias de clase serían anuladas. La diferencia radicaba entonces en el sujeto de este cambio ya que para la IMA este recaía en el niño y el maestro como un binomio identitario, mientras que para la ITE y la CSLA el rol predominante del proletariado (obrero y campesino) era indiscutible.

Hasta aquí lo dicho muestra la riqueza de un tema que aún merece futuras investigaciones. Por una parte y a modo de sugerencia, consideramos que debe profundizarse el análisis de los conceptos que se encuentran dentro de estos discursos y prácticas pedagógicas (como infancia, escuela, escolarización, maestro), siguiendo el modelo propuesto por Vilanou i Torrado para una historia de la educación conceptual y discursiva ${ }^{52}$. Por la otra, dado que los discursos no pueden estudiarse aisladamente, este análisis debería estudiar a los actores que participaron de esta trama, utilizando la prosopografía para delimitar y comprender quiénes son estos maestros y pedagogos que las integran.

\section{FUENTES}

Amauta, núm. 22, abril 1929

Boletín de la Liga de Educación Racionalista año 1, N. 3, enero 1915 y año 1 núm. 6, mayo 1915.

Boletín de la Internacional de los Trabajadores de la Enseñanza, año 4 , N. 1 enero-febrero 1930, año 4, N. 3, junio-julio 1930, año 5, N.1, febrero 1927.

Claridad, año 6, N. 145, 25 de octubre de 1927.

El trabajador, año II, núm. 17-18, junio y julio de 1929, .año II, N. 26-27, diciembre de 1929, año II N. 30, marzo-abril 1930.

Liberación, año I, N. 1-2, junio-julio de 1930, año I, N. 3, septiembre de 1930, año I, N. 5-6, noviembre-diciembre 1930, año II, N. 7-8, enero-febrero de 1931.

Renovación, año 6, núm. 61, enero 1928.

SINDICALISMO: resoluciones de la Confederación Sindical Latino Americana (1928), s.n.

${ }^{52}$ Ver, VILANOU i Torrado. (2006): Historia conceptual e historia de la educación en historia educativa, pp. 63-70. (general pp. 35-70) universidad de Salamanca. 


\section{REFERENCIA}

BARCOS, Julio. (1927): Cómo educa el estado a tu bijo. Buenos Aires, Editorial acción.

BARCOS, Julio. (1931): Política para intelectuales. Buenos Aires, s.n.

BELLO, María Eugenia. (2003): Educación y globalización. Los discursos educativos en Iberoamérica. Madrid, Anthropos Editorial.

BEIGEL, Fernanda. (2006): La epopeya de una generación y una revista: las redes editoriales de José Carlos Mariátegui en América Latina. Buenos Aires, Editorial Biblos.

BEIGEL Fernanda. (2003): El itinerario y la brújula. El vanguardismo estéticopolítico de José Carlos Mariátegui. Buenos Aires, Editorial Biblos.

CALVO ISAZA, Óscar Iván. (2005): Conocimiento desinteresado y ciencia americana. El congreso Científico (1898-1916) presentado en el seminario de historia intelectual de El Colegio de México, Consultado en http://shial. colmex.mx/textos/OscarCalvo2005.pdf.

CAMBRA BASSOLS, J. d. (1981): Anarquismo y positivismo: el caso Ferrer. Madrid, Centro de Investigaciones Sociológicas.

DE LUIS MARTÍN, Francisco. (1991): “La formación del obrero en la Europa de entreguerras (1919-1939): las principales instituciones socialistas y las Internacionales Obreras de la Enseñanza", en: Studia Histórica. Historia Contemporánea, IX.

DEL ROSAL, Amaro. (1963): Los Congresos Obreros Internacionales en el siglo XX. De 1900 a 1950. México, Editorial Grijalbo.

FERNÁNDEZ SORIA, J. M. (2006): "La nueva historia política de la educación”, en: Historia de la educación: revista interuniversitaria. No.25. Universidad de Salamanca.

KERSFFELD, Daniel. (2006-2007): “Tensiones y conflictos en los orígenes del comunismo latinoamericano: las secciones de la Liga Antiimperialista de las Américas" en Estudios interdisciplinarios de América Latina y el Caribe, Facultad de Humanidades Lester y Sally Entin, vol.18:2.En:http://www1. tau.ac.il $/$ eial $/$ index.php?option $=$ com_content\&task=view\&id=815\&Item $\mathrm{id}=314$

MARTÍNEZ TRUCCO, Amelia. (2004): Acción Gremial del Magisterio de Santa $\mathrm{Fe}$. Su trayectoria y aporte en la construcción del sistema educativo. Santa Fe, Universidad Nacional del Litoral.

MAYOL, A. (1978): Boletín de la "Escuela Moderna”. Barcelona, Tusquets.

PEDAGOGÍA PROLETARIA. INFORMES, TESIS Y DEBATES DE LAS JORNADAS PEDAGÓGICAS DE LEIPZIG. (1928): París, ediciones de la Internacional de Trabajadores de la Enseñanza. 
PITA GONZÁLEZ, Alexandra. (2009): La Unión Latino Americana y el Boletín Renovación. Redes intelectuales y revistas culturales en la década de 1920. México, El Colegio de México, La Universidad de Colima.

PORTANTIERO, Juan Carlos. (1978): Estudiantes y política en América Latina. El proceso de la reforma universitaria 1918-1938. México, Siglo XXI Editores.

PUIGGRÓS, Adriana. (2003): El lugar del saber: conflictos y alternativas entre educación, conocimiento y política. Buenos Aires, Editorial Galerna.

PUIGGRÓS, Adriana. (2006): Sujetos, disciplina y currículum en los orígenes del sistema educativo (1885-1916). Buenos Aires, Editorial Galerna.

ROCK, David. (1996): El radicalismo argentino. Buenos Aires, Amorrortu Editores.

TARCUS, Horacio. (2007): Diccionario biográfico de la izquierda argentina: de los anarquistas a la "nueva izquierda": 1870-1976. Buenos Aires, Emecé.

TEDEESCO, Juan Carlos. (1982): Educación y sociedad en la Argentina (18801900), Buenos Aires, Centro Editor de América Latina.

VAZ FERREIRA, Carlos. Lógica viva. (1979): Moral para intelectuales. (Prólogo de Manul Claps). Caracas, Biblioteca Ayacucho.

PITA GONZÁLEZ, Alexandra. (2011): “La internacionalización del magisterio americano: propuestas educativas y tensiones políticas" en: Revista Historia de la Educación Latinoamericana Vol. 13 No. 17, Tunja, Universidad Pedagógica y Tecnológica de Colombia, RUDECOLOMBIA, SHELA- HISULA. pp. 237-262 